\title{
https://doi.org/10.48009/2_iis_2006_344-349 \\ TRANSFORMING REMOTE SALES FORCE TRAINING: GUIDELINES FOR INTEGRATING E-LEARNING INTO AN EXISTING REMOTE SALES FORCE TRAINING PROGRAM - A CASE STUDY
}

\author{
Michael J. Donohoe DSc, mjddsc@gmail.com \\ Jeanne M. Baugh EdD, Robert Morris University, baugh@rmu.edu \\ Daniel R. Rota PhD, Robert Morris University, rota@ rmu.edu
}

\begin{abstract}
This qualitative, applied research project is a single case study of a medical device manufacturing company's sales training department. The research focused on how the sale's training department should consider the integration of e-learning into their sales training program without disrupting the existing instructor-led training. The data analysis produced guidelines for the sales training department to create a blended training model that would integrate elearning with live instruction. Other sales training departments may consider this research of value when navigating the 'how to' process of integrating e-learning into their instructor-led sales training programs.
\end{abstract}

Keywords: Distance Learning, E-learning, Remote Training

\section{INTRODUCTION}

Even financial communities and the federal government recognize the need for a well trained workforce. At a financial conference at Boston College on March 12, 2004, Federal Reserve Chairman Alan Greenspan stated, "The United States needs to better educate its workers and avoid the trappings of protectionism to fully flourish in a global economy" [6].

Companies rely on the skills and knowledge of their sales force to deliver products and services to the market place. Deploying and sustaining a highly skilled competitive sales force requires a strong management commitment towards effective initial and ongoing training solutions. Sales management is ultimately responsible for the direction and content of the training provided to the remote sales force, by directly or indirectly managing the training needs.

A remote training program is capable of delivering a continuous curriculum of training solutions to meet the needs of both new and veteran members of the deployed sales force. By providing product knowledge and sales skill training to the sales force, companies can position their products into the market place, knowing that the remote sales force has the necessary skills and information to make the sale, service their customers, and recognize additional sales opportunities.

The scope of this research project involved the remote sales force of a single business division working for a medical device manufacturing company. The remote sales force consisted of approximately 150 associates that worked from offices within their homes across the United States and Canada. The sales training department met the training challenges by using a standard delivery process of live face-to-face instructor led training (ILT) sessions. Theses training sessions were held primarily at the division's headquarters facility and at pre-scheduled remote meetings in various regions throughout the fiscal year.

The average remote sales force associate's territory is over three million dollars in annual forecasted revenue. On average, each member of the remotes sales force generated approximately $\$ 15,000$ to $\$ 25,000$ of revenue per day, depending upon the territory. Therefore, the time dedicated to the training needed to be both practical and effective, off-setting the missed selling opportunities when the sales representative was out of their territory. Additionally, the sales training department's curriculum had to be flexible enough to integrate new product training to warrant the travel and lodging costs associated with the training.

Peter M. Senge, defines a learning organization as "an organization that is continually expanding its capacity to create the future" $[8, \mathrm{p} .14]$. The sales training department realized in order to become a learning organization, the standard instructor-led training delivery would have to change or be complimented by another method.

\section{Distance Learning}

The Internet has enabled distance learning to evolve at a rapid pace, even though this form of education 
has been around for a long time. "At its most basic level, distance education takes place when a teacher and student(s) are separated by physical distance, and technology (i.e., voice, video, data, and print), often in concert with face-to-face communication, is used to bridge the instructional gap" [2]. Ideally the education is delivered electronically and does not require the student to attend the learning event.

\section{E-learning}

E-learning is the presentation of educational materials, content, or collaborative interaction for the purpose of knowledge transfer via the Internet. Of the various types of e-learning, the most widespread elearning method is asynchronous [1]. "E-learning is mostly associated with activities involving computers and interactive networks simultaneously" [4].

\section{Challenge of E-Learning Integration}

By integrating e-learning into an existing training curriculum, the goal would be to compress time and distance by educating the remote sales force on product knowledge and sales skills with a supportive e-learning strategy. E-learning would be available 24/7 from an Internet connection versus the traditional method of providing only face-to-face training. Gartner Group Research Analyst, M. Raskino, stated "Elapsed time is not digitally replicable and we cannot source more of it..." [7]. By reducing the scheduling gap in the delivery of training and using e-learning for select training courses, the sales training department could focus on specialized training needs while recovering productive time for the remote sales force [7].

A web-based article on the integration of e-learning into traditional teaching [5, p. 1] states: "Plenty of information can be found of how to build e-learning right from the beginning, but hardly anyone addresses the process of seamlessly integrating elearning into existing traditional training structures." The challenge of e-learning integration is: How does the sales training department plan on delivering a blended training solution, consisting of both elearning and instructor led training, without disrupting business and the remote sales force's training?

\section{RESEARCH DISCUSSION AND RESULTS}

This case study focused on how the training department would integrate e-learning into their existing, instructor-led, remote sales force training program. The researcher gathered detailed information on how the sales training department functioned within the business environment and how training was provided in the current 'as is - design.' The researcher also conducted in-depth interviews with selected members of the remote sales force to identify future training needs in the 'to be - design.'

During the period of the case study, the business unit's sales force management team was structured as a VP of Sales with the following direct reports: Director of National Accounts, nine Regional Managers and a Director of Sales Training. The balance of the 125 sales associates reported into the national accounts director or one of nine regional managers. In addition to the remote sales force, a technical engineering group (nine field technicians) provided direct sales support. The candidates selected for participation in this study were composed of a broad cross section sample of all the different roles within the sales force and sales training departments. Twenty four potential participants were contacted by the researcher via e-mail and voice mail messages. Table 1, identifies the job titles of the 17 interviewees who eventually participated:

Table 1. Interview Candidates Table

\begin{tabular}{|l|c|}
\hline Interview Job Title & $\begin{array}{c}\text { Number of Interviews } \\
\text { per Job Title }\end{array}$ \\
\hline $\begin{array}{l}\text { Director of Sales } \\
\text { Development }\end{array}$ & 1 \\
\hline $\begin{array}{l}\text { Sale Training } \\
\text { Specialists }\end{array}$ & 2 \\
\hline $\begin{array}{l}\text { Director of National } \\
\text { Accounts }\end{array}$ & 1 \\
\hline $\begin{array}{l}\text { National Account } \\
\text { Managers }\end{array}$ & 3 \\
\hline $\begin{array}{l}\text { Regional Account } \\
\text { Managers }\end{array}$ & 4 \\
\hline $\begin{array}{l}\text { Remote Sales } \\
\text { Associates }\end{array}$ & 4 \\
\hline $\begin{array}{l}\text { Marketing Product } \\
\text { Managers }\end{array}$ & 2 \\
\hline
\end{tabular}

Each participant was interviewed individually, faceto-face, and all interviews were conducted the same, using a survey scripted series of questions.

The interview questions consisted of four groups: (a) background information-demographics, (b) general questions-learning agility, (c) 'as is' remote sales training, and (d) 'to be' remote sales training. Each interview was tape recorded. During all 17 interviews, the researcher captured notes using a hard copy of the survey questions. These notes captured key points from the participant's auditory responses, as well as non-verbal communication behaviors, 
providing a greater qualitative experience for data collection.

\section{Data Analysis Results}

By creating data themes for data interpretation and representation, the researcher performed a detailed data analysis to "treat the evidence fairly, produce compelling analytical conclusions, and rule out alternative interpretations" $[9, \quad$ p. 11]. The researcher's initial analysis identified 31 data themes. The researcher created an affinity diagram with all 31 data themes. The affinity diagram, Figure, 1 then identified four categorical data themes: (a) learning agility, (b) training solutions, (c) roles and responsibilities, and (d) expectations.

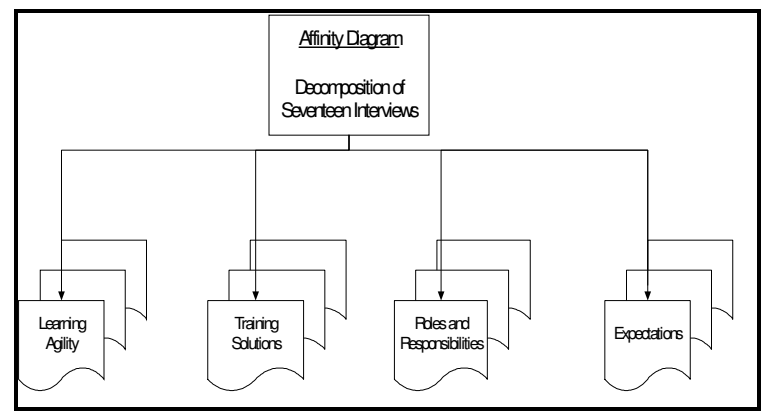

Figure 1. Affinity Diagram of 4 Categorical Themes

\section{Training Solutions}

A majority of the interview questions focused on the 'as is' current and 'to be' future approaches towards training. The respondents saw great value in accessing a sales training solution for: (a) training anytime and anywhere, (b) the reduction in travel costs, and (c) self-paced training supervised by a manager or mentor versus a classroom trainer. In a blended approach to training, a mix of both instructor lead training as well as e-learning would be presented to the remote sales force as a coordinated training solution.

\section{Roles and Responsibilities}

The data analysis of the various roles and responsibilities of the participants in the current training environment is an important component of the researcher's analysis. Particularly when striving to identify future 'blended learning' training integration guidelines. By better understanding the human element within this research project, realistic guidelines were developed that incorporated the 'people' issues as perceived by the researcher's interpretation of the interviewees' responses.

\section{Expectations}

The expectations focus mainly on what the future training solution may be. However, before reviewing the data on the 'to be' training, it was important to question the expectations of the current training offered.

\section{Data Theme Representation}

After the data themes were consolidated from 31 to four categorical themes, the researcher created Ishikawa diagrams for the two key concepts that emerged (a) Blended Learning and (b) Organizational Change. Included in the diagrams were the four categorical data themes combined with research content discovered during the literature review. This process aided in creating key concepts to help develop e-learning integration guidelines for the sales force management group.

For the sales training department to move forward with the action of integrating e-learning into the existing remote sales force training program, they needed to understand two key concepts before making any decisions to move forward with their plan. First, they needed to understand 'blended learning' as applied to the existing remote sales training program. Second, they needed to understand the effect 'change' would have on the people and the organization.

\section{Blended Learning}

The key concept of blended learning is represented visually below in Figure 2: Blended Learning Ishikawa Diagram. The diagram is a combination of the four categorical data themes and various related ideas discovered in the literature review research.

The four sub groups, (a) Adult Learning, (b) Training Solutions, (c) Expectations, and (d) Learning Management Systems, represented the mixture of ideas that focused on the key concept of blended learning to assist the researcher with the development of E-learning Integration Guidelines. Figure 2: Blended Learning Ishikawa Diagram maps several key concepts regarding blended learning. 


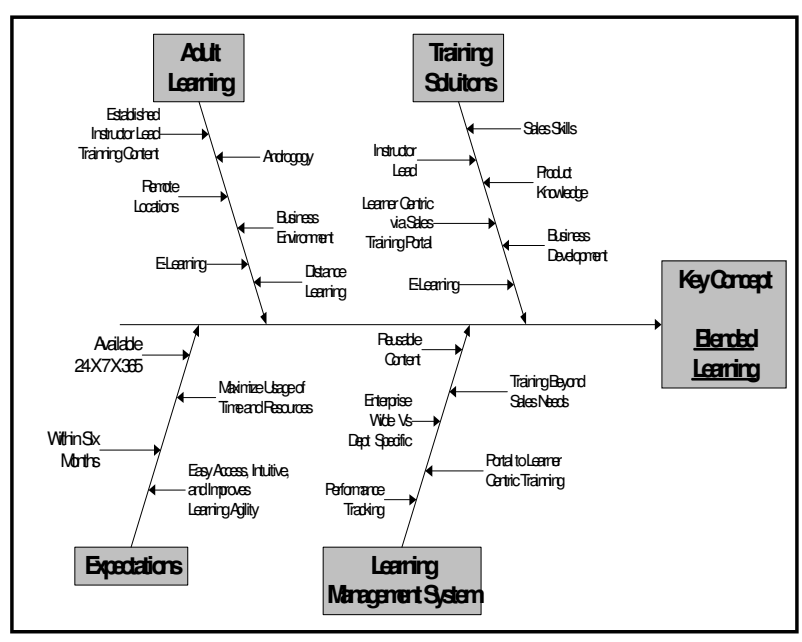

Figure 2. Blended Learning Ishikawa Diagram

The idea of shifting some of the training, now being provided by instructor-led training sessions, to elearning sessions that were requested and launched by the learner was very attractive to the sales training department. Several expectations of e-learning were: (a) saved travel time and resources, (b) access was simple and available $24 \times 7$, (c) learner centric, (d) beyond sales training and product knowledge to include business development skills, and (e) employees training performance would be better tracked. Several of these features could be realized through designing incrementally e-learning training sessions one at a time or on a larger scale integration using a learning management system (LMS) for the remote sales force. The success, using either approach, would depend upon the commitment and vision of the sales management and training departments. As a recommended strategy, the business unit should initiate, on a smaller scale, an elearning proof-of-concept project. Thinking big and acting small, until they are successful in providing online training programs, is the advice provided by Brad Hall when companies are first getting started and considering e-learning or a learning management system [3].

In addition to an e-learning proof-of-concept project, it is the researcher's opinion that at a minimum, the sales training department would need to assess (a) the skills of the training staff toward e-learning instruction and content creation, (b) the portability of existing sales training courses from instructor-led course content to e-learning course content, and (c) the technology skills of the remote sales associates to access the e-learning solutions. Upon completion of the assessments of the three areas, the sales training department would have a better idea of the challenges and efforts needed to integrate e-learning into an existing remote sales force training program.

\section{Organizational Change}

The researcher viewed the remote sales force as a unique, competitive group with only one purpose presenting and selling products to their customers. Changing the culture to recognize the value of training, within an established organization, is difficult if all groups do not fully understand the value or driving requirements.

The key concept, organizational change, is a focus area for the creation of E-learning Integration Guidelines. In Figure 3, the five sub groups are (a) Learning Agility, (b) Sales Training Department, (c) Sales Management, (d) Remote Sales Force, and (e) Technology Usage, representing the areas that organizational change impacted during the creation of the E-Learning Integration Guidelines.

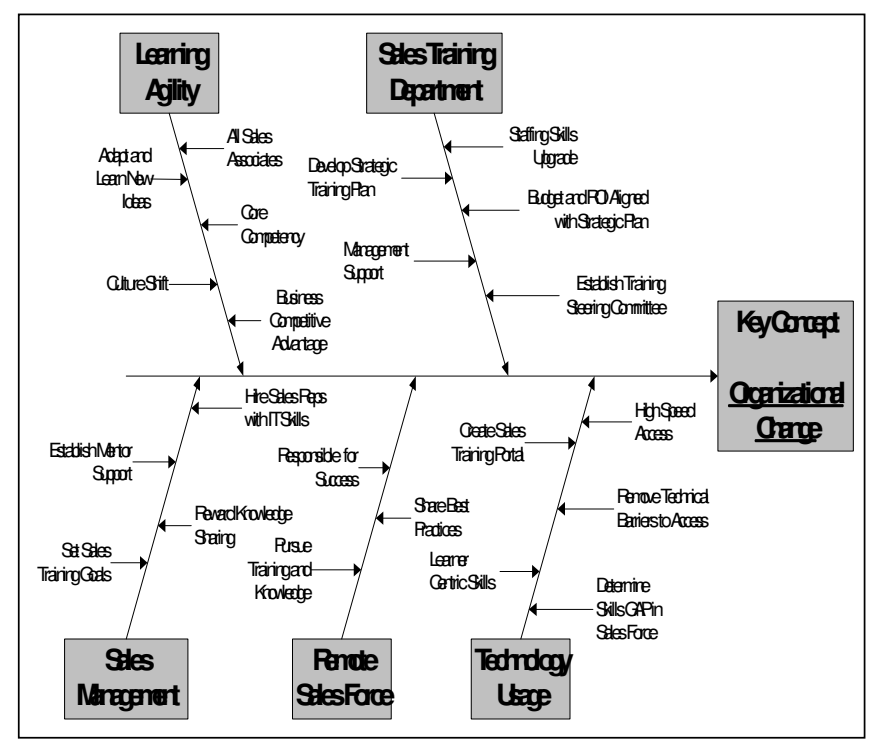

Figure 3. Organizational Change Ishikawa Diagram

\section{RECOMMENDATIONS FOR INTEGRATING E-LEARNING FOR REMOTE SALES TRAINING}

\section{Guidelines}

1. Create a Sales Training Steering Committee

1.1. Committee sponsors - VP of sales and director of sales training 
1.2. Committee membership should be director of sales training, two sales trainers, two regional sales managers, two remote sales associates, one marketing product manager, one information technology business analyst, and the director of corporate learning

1.3. The committee will be empowered to develop a charter to assess and evaluate the existing training content for usability, review/approve the director of sales strategic training plan, assess e-learning solutions (including learning management systems), and provide guidance for resource investment and optimization. In addition the sales training steering committee will:

1.3.1. establish key performance indicators ( KPI) measurements of blended learning solution, through pre \& post testing on sales training content to measure the effectiveness of the blended learning experience

1.3.2. establish an effective communication plan to the remote sales associates, continuously communicating the sales training strategy to the remote sales associates

1.3.3. recognize that organizational change may be required to introduce a blended learning solution and accept that organizational changes must come from within to be effective

2. Clarify Role of the Director of Sales Training

2.1. Promotes the creation of remote sales training steering committee

2.2. Participates and report the steering committee status to the VP of sales

2.3. Creates a three year strategic training plan for the remote sales force, recognizing appropriate courses, tasks, responsibilities, project timeline, and present to steering committee for review / approval

2.4. Promotes blended learning solution, demonstrate success by starting small and expanding to encompass the entire sales department, leverage successes and identify best practices

2.5. Manages the sales training department, exceed sale management and the remote sales force training expectations, while delivering training solutions, anytime and anywhere $24 / 7$

2.6. Shifts the current sales training staff skills to managing and understanding e-learning functions, delivering higher level instructor lead training sessions, as well as developing course authoring skills related to the business

2.7. Hires qualified trainers and staff with the necessary skills capable of developing and managing remote sales blended training content and solutions

2.8. Promotes learning agility to remote sales force

2.9. Is responsible for the management of all remote sales blended training content and solutions

\section{Assess the Current 'as is' Environment}

3.1. Assess and catalog all existing training content, determine what is kept, modified, discarded, or converted to e-learning material and content.

3.2. Assess and define the functional requirements for the integration of elearning into the remote sales force

3.3. Assess the computing technology at all levels, from internal servers where the sales training content resides, outward to the remote sales associates (laptop, skills and type of connection)

\section{Create Sales Training Portal}

4.1. Create a sales training portal with the following components:

4.1.1. Single sign-on authorization that is customized to the users security profile to provide all 'learning centric' needs of the remote sales associate in a secure environment

4.1.2. learning management system (LMS) providing the capability for the training management support systems to track and monitor remote sales associates performance measurements

4.1.3. one stop location for all remote sales force associates training needs with meaningful content (marketing materials, robust internal content library, e-learning courses, training schedules, peer chat, external training content, and workflow (scenario) learning)

4.2. Implementation process should be four phases, time-boxed in weeks or months, with feedback loops, and sign off by sales training steering committee

4.2.1. Phase One - Business Blueprint (functional review, scope validation, design of solution, determine rollout 
to users and system interface training awareness)

4.2.2. Phase Two - Realization (building the system, system testing, technical development)

4.2.3. Phase Three - Final Prep and Communication Plan (loading courseware content, verification and validation, and cut-over strategy)

4.2.4. Go Live

4.2.5. Phase Four - Operational Support (provide post system go live support and stabilization)

\section{Desired Outcomes Leveraging E-Learning}

5.1. The goal of the remote sales training portal is to promote a memorable and repeatable experience every time the remote sales associate accesses training.

5.2. Once the remote sales training portal is designed and deployed, the return on investment (ROI) can be significantly reduced by extending the application into other areas of the enterprise.

5.3. Create a blended learning environment for the remote sales force associates, that is abundant, pervasive and naturally into people's lives.

\section{CONCLUSIONS}

The strategic advantage of e-learning is to compress both time and distance in the delivery of training content to the remote sales force. The sales training department must realize that e-learning can make a significant difference by providing an enhanced training environment to the remote sales force. However, without having a strategic training plan in place, identifying the content per training type (elearning versus traditional training), combined with the prioritization of training delivery, it is possible that the remote sales training support effort could fail. It is imperative to the marketing department's product management that the sales force be fully knowledgeable of the product prior to customer rollout.

\section{Future Research}

Future research areas of consideration would be to take the recommended guidelines, using a qualitative action research methodology, and collaborate with a Sales Training Department to support the remote sales force. The goal would be to initiate an active learning management system without impacting negatively the existing remote sales training mission. Once the sales force learning management system would be functionally operational, other similar business units would be presented with the project outcomes for future implementation considerations.

\section{REFERENCES}

1. Anonymous. (2003). What is e-learning? Retrieved January 21, 2004, from http://www.asiaelearning.net/content/aboutEL/index.html

2. Anonymous. (2004). Distance education at a glance -- College of Engineering University of Idaho. Retrieved January 9, 2004, from http://www.uidaho.edu/eo/dist1.html

3. Gilhooly, K. (2001). Making e-learning effective. Retrieved November 10, 2003, from http://www.computerworld.com/careertopics/car eers/training/story/0,10801,62099,00.html

4. Machado, S. T. a. P. (2003). E-learning, online learning, web-based learning, or distance learning; Unveiling the ambiguity on current technology. Retrieved January 7, 2004, from http://www.elearnmag.org/subpage/sub_page.cf $\mathrm{m}$ ? section $=3 \&$ list_item $=6 \&$ page $=1$

5. Pacnik, H. (2002). Practical experience of a seamless integration of e-learning into traditional teaching. Retrieved December 15, 2003, 2003, from

http://www3.cti.ac.at/icl/archive/presentation/pac nik.pdf

6. Pope, J. (2004). Greenspan urges more worker education. Retrieved March 12, 2004, from http://www.ajc.com/business/content/business/ap /ap_story.html/Financial/AP.V7781.APGreenspan.html

7. Raskino, M. (2002). Nine key principles of the real-time enterprise. Retrieved November 10, 2003, from www.gartner.com

8. Senge, P. M. (1990). The fifth discipline: The art and practice of the learning organization. New York: Doubleday/Currency.

9. Yin, R. K. (2003). Case study research: design and methods (3rd ed.). Thousand Oaks, CA: Sage Publications. 